“C 2017 IEEE. Personal use of this material is permitted. Permission from IEEE must be obtained for all other uses, in any current or future media, including reprinting/republishing this material for advertising or promotional purposes, creating new collective works, for resale or redistribution to servers or lists, or reuse of any copyrighted component of this work in other works." 


\title{
Comparison of Torque Characteristics for a Novel Segmented and a Conventional Switched Reluctance Motors
}

\author{
Yichen Shen ${ }^{1}$, Xiaodong Sun ${ }^{1,2 *}$, Long $\mathrm{Chen}^{2}$, Zebin Yang ${ }^{3}, \mathrm{Ke} \mathrm{Li}^{3}$, Jianguo $\mathrm{Zhu}^{4}$, and Youguang $\mathrm{Guo}^{4}$ \\ ${ }^{1}$ School of Automobile and Traffic Engineering, Jiangsu University, Zhenjiang 212013, China \\ ${ }^{2}$ Automotive Engineering Research Institute, Jiangsu University, Zhenjiang 212013, China \\ ${ }^{3}$ School of Electrical and Information Engineering, Jiangsu University, Zhenjiang 212013, China \\ ${ }^{4}$ School of Electrical, Mechanical and Mechatronic Systems, University of Technology, Sydney, Sydney, NSW 2007, Australia
}

\begin{abstract}
The extensive applications of switched reluctance motor (SRM) have been limited due to its drawback of torque ripple. Thus, the reduction of torque ripple is an important problem in studying the SRM. A novel 16/10 segmented SRM (SSRM) is proposed in this paper. The proposed SSRM performs well in terms of torque ripple and tolerant-fault characteristic. The stator of the proposed structure is constructed from exciting and auxiliary stator poles, while the rotor consists of a series of discrete segments. Moreover, the torque ripple is evaluated by comparing with the conventional 8/6 SRM. Finally, the tolerant-fault characteristic of the proposed SSRM and conventional SRM are compared as well. The finite element method (FEM) is employed to demonstrate the prominent advantages of static and dynamic characteristics of the proposed SSRM.
\end{abstract}

Index Terms-- segmented rotor, switched reluctance motor, torque ripple, tolerant-fault.

\section{INTRODUCTION}

The robustness, reliability, and simplicity of the SRM make it an ideal candidate for using in the BSG (Beltdriven Starter Generator) [1]. However, due to its strongly nonlinear behavior, its modeling and control are more complex and its torque ripple is difficult to solve [2]. In this study, a novel 16/10 segmented switched reluctance motor (SSRM) is proposed for the BSG. The studied BSG in this paper is a 60-VDC system that performs two functions. One function $(0-6000 \mathrm{r} / \mathrm{m})$ is to start the engine with at least $25 \mathrm{Nm}$ torque. The other $(6000-16000 \mathrm{r} / \mathrm{m})$ is to generate $60 \mathrm{~V}$ power which is reduced to $12 \mathrm{~V}$ power through DC/DC inverter for battery and other application devices in hybrid electrical vehicles.

Normally, the SRM suffers from high torque ripples, and loud noise limits its range of application in industrial and domestic applications. In order to increase the output torque of the motor, the SRM mostly works in the saturation region of the magnetic characteristics [3, 4]. Therefore, torque ripple of SRM can be improved by designing machine structures and control approaches [5, 6]. The proposed SSRM is a novel structure, detail analysis should be done to justify the improvement of the proposed SSRM in terms of the torque ripple and output torque [7-9].

In this paper, the comparison of the proposed SSRM and the conventional SRM will be provided to study the advantages of the proposed SSRM in terms of torque ripple. For a fair comparison, the two motors are designed to have the same overall dimensions and operating conditions. In section II, the structure of the proposed SSRM is introduced. The static characteristics and the torque ripple characteristic of the proposed SSRM are analyzed specifically in Section III. The SSRM and the SRM are analyzed by means of FEM. Meanwhile, the tolerant-fault characteristic of the SSRM is analyzed when there is something wrong with one phrase. Finally, Section IV gives the conclusion.

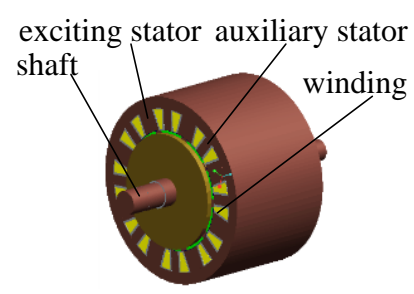

(a)

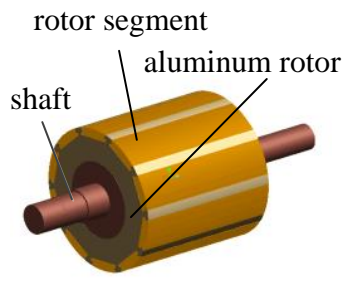

(b)
Fig. 1. 3-D dimensions of the proposed SSRM: (a) stator, (b) rotor.

TABLE I

SPECIFICATIONS OF THE PROPOSED SSRM

\begin{tabular}{|c|c|c|c|}
\hline Parameters & Value & Parameters & Value \\
\hline Number of phase & 4 & Stator pole $\operatorname{arc}\left(^{\circ}\right)$ & $\begin{array}{c}21.38 / 10 \\
7\end{array}$ \\
\hline $\begin{array}{l}\text { Outer radius of } \\
\text { stator }(\mathrm{mm})\end{array}$ & 64 & Rotor pole arc $\left(^{\circ}\right)$ & 26.64 \\
\hline $\begin{array}{l}\text { Outer radius of } \\
\text { rotor }(\mathrm{mm})\end{array}$ & 41 & Number of turns & 26 \\
\hline $\begin{array}{l}\text { Length of stack } \\
(\mathrm{mm})\end{array}$ & 80 & $\begin{array}{l}\text { Wire diameter } \\
(\mathrm{mm})\end{array}$ & 2 \\
\hline $\begin{array}{l}\text { Length of air gap } \\
(\mathrm{mm})\end{array}$ & 0.25 & Slot factor & 0.82 \\
\hline $\begin{array}{l}\text { Yoke thickness of } \\
\text { stator }(\mathrm{mm})\end{array}$ & 8 & $\begin{array}{l}\text { Resistance per } \\
\text { phase }(\mathrm{m} \Omega)\end{array}$ & 18.5 \\
\hline
\end{tabular}

\section{STRUCTURE AND SPECIFICATION: PROPOSED SSRM}

The proposed SSRM has sixteen stator poles and ten rotor poles as shown in Fig. 1. Different from conventional structures, the stator is constructed from two types of stator poles: exciting and auxiliary poles. The exciting poles are wound by the concentrated windings which are short and nonoverlap the end-windings, while the auxiliary stator poles are not wound by any windings, 
only providing the flux return path. Moreover, from Fig. 1 , it can be seen that the rotor is composed of a series of discrete segments and each rotor segment is embedded in a rotor block which is made of aluminum and is used to magnetically isolate from its neighbors $[10,11]$. Table I shows the specifications of the proposed SSRM.

\section{ANALYSIS OF TORQUE RIPPLE FOR SSRM}

It was reported that use of a higher number of rotor poles can increase the torque output [12]. In this paper, the cost and manufacturing process requirement of the SSRM are considered, and a novel 16/10 SSRM is designed. The output torque of the SSRM is mainly due to its air gap flux densities, stator and rotor poles, and polearc coefficients [13, 14]. Therefore, the static and dynamic characteristics of the proposed SSRM are analyzed in this section.

\section{A. Mathematical Equations}

When ignoring fringing effect and saturation effects, the torque $\mathrm{T}$ in phase- $\mathrm{A}$ is explained as follows:

$$
T=\frac{1}{2} \frac{\partial L}{\partial \theta} i^{2}
$$

When the rotor position is considered, the average torque $T_{a v}$ can be written in terms of aligned and $\phi \mathrm{a}$ unaligned $\phi u$ flux linkages as

$$
T_{a v}=\left(\phi_{a}-\phi_{u}\right) N_{r}
$$

Aligned flux is given as

$$
\phi_{a}=B_{g} \frac{D}{2} L k_{1} \frac{\pi}{N_{r}}
$$

Therefore, the average torque $T_{a v}$ can be obtained by

$$
T_{a v}=B_{g} \frac{D}{2} L k_{1} \pi-\phi_{u} N_{r}
$$

The torque ripple ratio $\mathrm{KT}$ is defined as the ratio of the peak-to-peak value to the average value, it can be written as:

$$
K_{T}=\frac{T_{\max }-T_{\min }}{T_{a v}}
$$

where $B_{g}$ represents the air gap flux density, $D$ is the air gap diameter, $L$ is the stack length, $k_{l}$ is the ratio of rotor pole arc to rotor pole pitch, $N_{r}$ is the numbers of rotor segments.

\section{B. Static Characteristics}

Static characteristics of the SSRM include magnetic flux density, inductance and torque profiles, which are shown as Fig. 2. From Fig. 2(a) and (b), it can be seen that the average flux density in the stator yoke when phase $\mathrm{A}$ is excited at aligned position is about $1.4 \mathrm{~T}$, which satisfies the designed requirement [15]. Fig. 2(c) and (d) show the inductance and torque profile of the proposed SSRM at the excitation from 6A to 31A, respectively. As expected, the average torque $T_{a v}$ reaches about $4 \mathrm{Nm}$ at $31 \mathrm{~A}$.

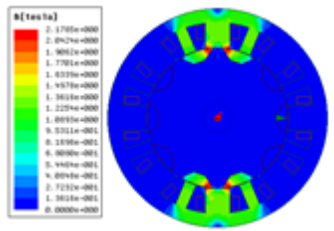

(a)

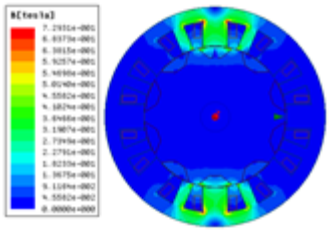

(b)

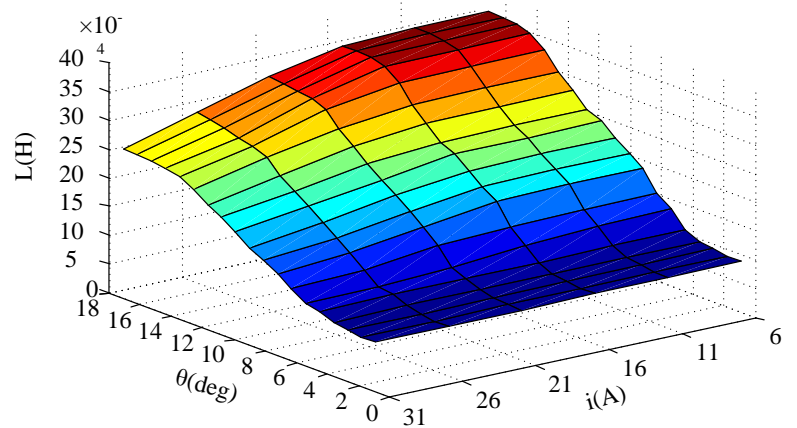

(c)

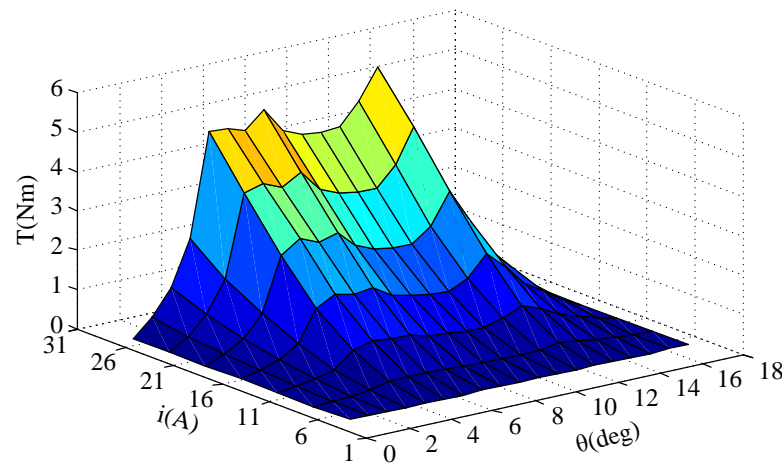

(d)

Fig. 2. Static characteristics of the SSRM.(a) Magnetic flux density at aligned position, (b) Magnetic flux density at unaligned position, (c) Inductance, (d) Torque.

\section{Dynamic Characteristics}

The dynamic characteristics of the SSRM shown in Fig. 3 are based on an external asymmetric converter circuit at rated condition, the turn on and off angles are $4^{\circ}$ and $12^{\circ}$ respectively.

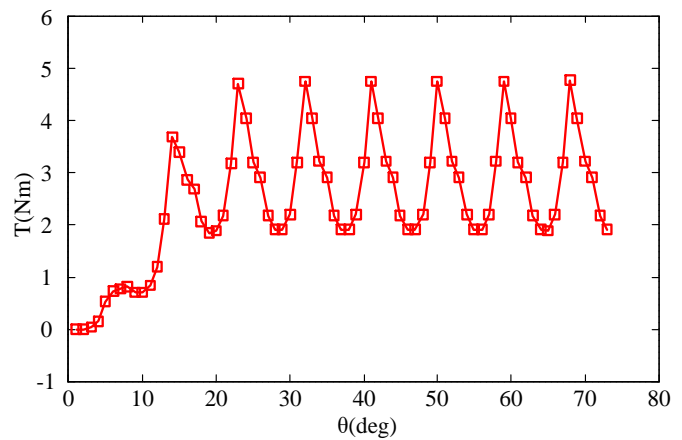

Fig. 3. Torque of the proposed SSRM at rated condition.

The average torque of the proposed SSRM can be estimated by the torque profile shown in Fig. 3. And the torque ripple ratio $K_{T}$ is calculated by (5). The average torque is about $3.101 \mathrm{Nm}$. The torque ripple ratio is about 0.921 . 
D. Comparison of Four-phase 8/6 Conventional SRM and The Proposed SSRM

The comparison between both motors is performed by using the same overall dimensions and operation conditions for the fair results [16]. The dynamic torque of the conventional SRM shown in Fig. 4 is based on an external asymmetric converter circuit at rated condition, the turn on and off angles are $-4^{\circ}$ and $15.5^{\circ}$ respectively.

The average torque of the conventional SRM can be estimated by the torque profile. And the torque ripple ratio $K_{T}$ is calculated by (5). The average torque is about $2.924 \mathrm{Nm}$. The torque ripple ratio is about 1.151.

Table II shows the advantages of the proposed SSRM by the comparison of the proposed SSRM and the conventional SRM. It can be found that the average output torque with rated current injection equals to 3.101 $\mathrm{Nm}$ for the proposed SSRM. When the conventional SRM is excited by same phase current, the average output torque is $2.924 \mathrm{Nm}$. The average output torque of the proposed SSRM is higher. And the torque ripple ratio $K_{T}$ of the proposed SSRM is 0.921 , while the value is 1.151 for the conventional SRM. From Table II, it is obvious that the dynamic performance of the proposed SSRM is superior to that of the conventional SRM.

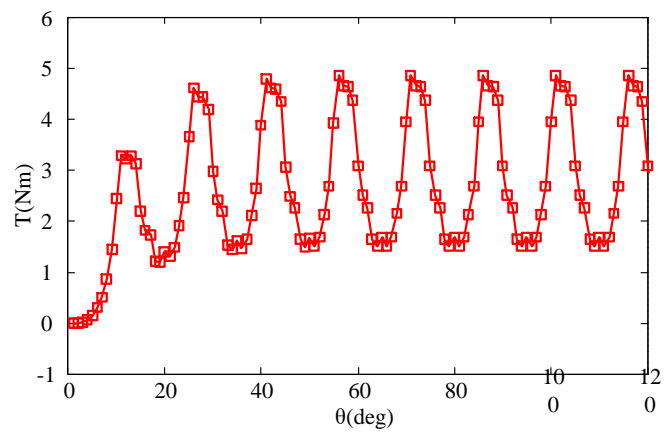

Fig. 4. Torque of the conventional SRM at rated condition.

TABLE II

TORQUE CHARACTERISTICS OF THE PROPOSED SSRM AND THE CONVENTIONAL SRM

\begin{tabular}{lllll}
\hline \hline Type & $T_{\max }(\mathrm{Nm})$ & $T_{\min }(\mathrm{Nm})$ & $T_{a v}(\mathrm{Nm})$ & $K_{T}$ \\
\hline Proposed SSRM & 4.751 & 1.895 & 3.101 & 0.921 \\
Conventional SRM & 4.862 & 1.496 & 2.924 & 1.151 \\
\hline \hline
\end{tabular}

\section{E. Tolerant-fault Characteristics}

The comparison of the proposed SSRM shown in Fig. 5 and 6 is used to estimate the tolerant-fault ability. The conventional SRM is a four-phase $8 / 6$ structure with the same overall dimensions and operation conditions.

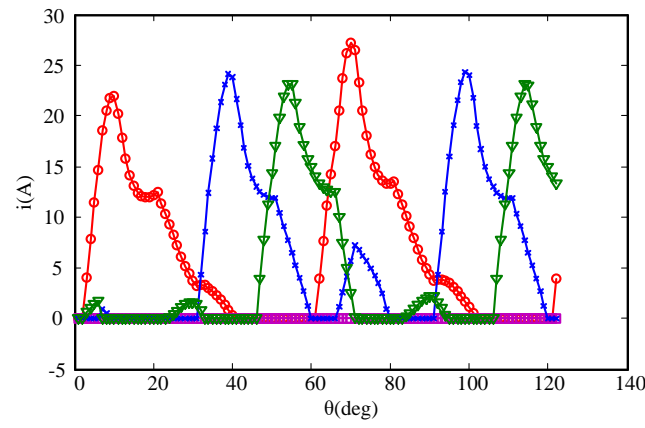

(a)

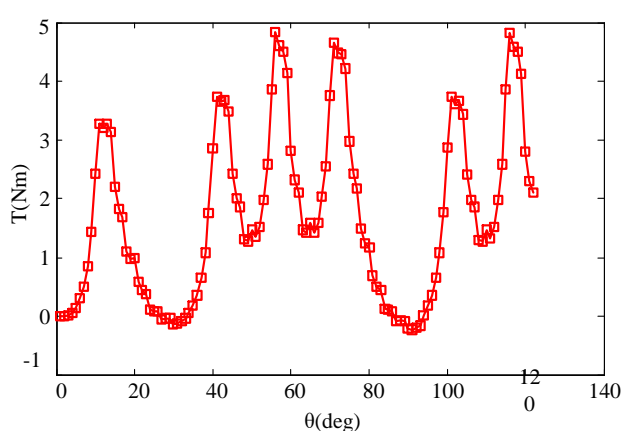

(b)

Fig. 5. Characteristics of the proposed SSRM with phase B shortcircuits: (a) Currents, (2) Torque.

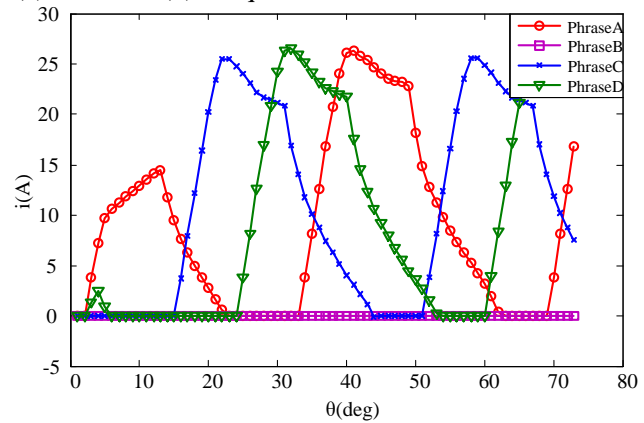

(a)

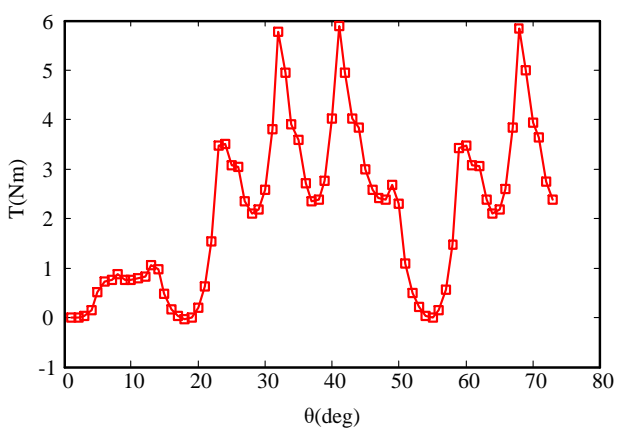

(b)

Fig. 6. Characteristics of the the conventional SRM with phase B shortcircuits: (a) Currents, (b) Torque.

In order to study the tolerant-fault characteristic of the proposed SSRM, the circuit of phrase B is cut off. It can be seen in Fig. 5 (a) that the current of the other phrases are not affected by the phrase B. The maximum current of the phase $B$ in the SSRM is almost OA, while the maximum current of the phase $\mathrm{B}$ in the conventional SRM is about 3.1A in Fig. 6 (a). This reveals that the windings of the proposed SSRM are magnetically isolated from each other to a greater degree than that in the conventional SRM. In addition, as shown in Fig. 5 (b) and Fig. 6 (b), the average torque in the proposed SSRM is bigger than the one in the conventional SRM, but the ripple torque is smaller. The SSRM shows the tolerantfault ability to be better when one phrase doesn't work.

\section{F. Manufactured SSRM}

As shown in Fig. 7, the proposed SSRM has been manufactured. The material of the stator and rotor segments is the DW310 -35 silicon iron sheets. The actual characteristics of the proposed SSRM will be measured in the next work $[17,18]$. And the measured results will be 
compared with the simulation results.

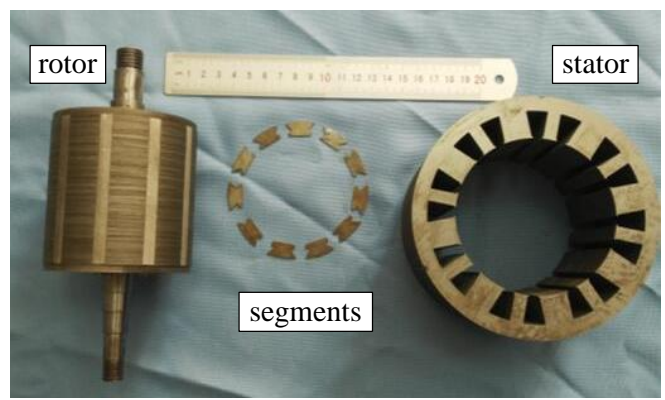

Fig. 7. The proposed SSRM: rotor, stator, and segments.

\section{CONCLUSION}

In this study, a novel 16/10 SSRM is proposed. The design of this proposed structure is illustrated and the static and dynamic characteristics are analyzed. Then, the torque characteristics of SSRM obtained from the FEM solution are used to perform torque ripple analysis. The SSRM contributes lower torque ripple when compared to the conventional SRM. Ultimately, the comparison between the SSRM and the conventional SRM highlights the advantages of the SSRM in the fault-tolerant characteristic. The proposed SSRM performs better torque ripple, output torque and fault-tolerant characteristics.

\section{ACKNOWLEDGMENT}

This work was supported by the National Natural Science Foundation of China (51305170 and 51475214), the Natural Science Foundation of Jiangsu Province of China (BK20170071 and BK20141301), the Key Project of Natural Science Foundation of Jiangsu Higher Education Institutions (17KJA460005), the China Postdoctoral Science Foundation (2016M601726 and 2015T80508), the Six Categories Talent Peak of Jiangsu Province (2015-XNYQC-003, 2014-ZBZZ-017, and 2016-GDZB-096), Zhenjiang Key Research and Development Project (GY2016003), the "333 project" of Jiangsu Province (BRA2017441), and the Priority Academic Program Development of Jiangsu Higher Education Institutions (PAPD).

\section{REFERENCES}

[1] N. Wehmeier, B. Lim, A. Merkle, A. Tempez, S. Legendre, H. Wagner, A. Nowack, T. Dullweber, and P. P. Altermatt, "PECVD BSG diffusion sources for simplified highefficiency N-PERT BJ and BJBC solar cells," IEEE $J$. Phtovoltaics, , vol. 6, no. 1, pp. 119 - 125, Jan. 2016.

[2] X. Sun, L. Chen, Z. Yang, H. Zhu. "Speed-sensorless vector control of a bearingless induction motor with artificial neural network inverse speed observer," IEEE/ASME Trans. Mech., vol. 18, no. 4, pp. 1357-1366, Aug. 2013.

[3] R. Mikail, I. Husain, Y. Sozer, M. Islam, and T. Sebastian, "Torque-ripple minimization of switched reluctance machines through current profiling," IEEE Trans. Ind. Appl., vol. 49, no. 3, pp. 1258-1267, May. 2013.

[4] J. Ye, B. Bilgin, and A. Emadi, "An extended-speed lowripple torque control of switched reluctance motor drives,"
IEEE Trans. Power Electron., vol. 30, no. 3, pp. 14571470, Mar. 2015.

[5] H. P. Chi, R. L. Lin, and J. F. Chen, "Simplified fluxlinkage model for switched-reluctance motors," IEEE Proc. Electr. Power Appl., vol. 152, no. 3, pp. 577-583, May. 2005.

[6] M. Dowlatshahi, S. M. Saghaiannejad, J. W. Ahn, and M. Moallem, "Minimization of torque-ripple in switched reluctance motors over wide speed range," J. Electr. Eng. Technol., vol. 9, no. 2, pp. 478-488, Jul. 2014.

[7] G. Lei, Y. G. Guo, J. G. Zhu, X. M. Chen, and W. Xu, "Sequential subspace optimization method for electromagnetic devices design with orthogonal design technique," IEEE Trans. Magn., vol. 48, no. 2, pp. 479482, Feb. 2012.

[8] X. Sun, Z. Shi, L. Chen, and Z. Yang, "Internal model control for a bearingless permanent magnet synchronous motor based on inverse system method," IEEE Trans. Energy Convers., vol. 31, no. 4, pp. 1539-1548, Dec. 2016.

[9] X. Sun, B. Su, L. Chen, Z. Yang, X. Xu, and Z. Shi, "Precise control of a four degree-of-freedom permanent magnet biased active magnetic bearing system in a magnetically suspended direct-driven spindle using neural network inverse scheme," in Proc. Mechanical Systems and Signal Processing (MSSP 2017), vol. 88, pp. 36-48, May. 2017.

[10] H. Zhang, D.H. Lee, C.W. Lee, and J.W. Ahn, "Design and performance analysis of a segmental rotor type $12 / 8$ switched reluctance motor," J. Power Electron., vol. 14, pp. 1-6, Jun. 2014.

[11] J. Oyama, T. Higuchi, T. Abe, and K. Tanaka, "The fundamental characteristics of novel switched reluctance motor with segment core embedded in aluminum rotor block," in Proc. IEEE Elec. Mach. Sys. Conf., vol. 1, pp. 515-519, Nov.2006.

[12] V. Ralla, and B.G. Fernandes, "Design procedure of segmented rotor switched reluctance motor for direct drive applications," IET Electric Power Appl., vol. 8, pp. 77-88, May. 2014

[13] X. Sun, L. Chen, H. Jiang, Z. Yang, J. Chen, and W. Zhang. "High-performance control for a bearingless permanent magnet synchronous motor using neural network inverse scheme plus internal model controllers," IEEE Trans. Ind. Electron., , vol. 63, no. 6, pp. 3479-3488, June. 2016.

[14] X. Sun, L. Chen, Z. Yang, "Overview of bearingless permanent magnet synchronous motors," IEEE Trans. Ind. Electro., vol. 60, no. 12, pp. 5528-5538, Dec. 2013.

[15] R. Mikail, I. Husain, M. Islam, Y. Sozer, and T. Sebastian, "Four-quadrant torque ripple minimization of switched reluctance machine through current profiling with mitigation of rotor eccentricity problem and sensor errors," IEEE Trans. Ind. Appl., vol. 51, no. 3, pp. 2097-2104, May. 2015.

[16] G. Lei, G. Y. Yang, K. R. Shao, Y. G. Guo, J. G. Zhu, and J. D. Lavers, "Electromagnetic device design based on RBF models and two new sequential optimisation strategies," IEEE Trans. Magn., vol. 46, no. 8, pp. 3181-3184, Sep. 2010.

[17] G. Lei, C. C. Liu, J. G. Zhu, and Y. G. Guo, "Multilevel robust design optimization of a superconducting magnetic energy storage based on a benchmark study," IEEE Trans. Appl. Supercon., vol. 26, no. 7, pp. 1-5, Oct. 2016.

[18] G. Lei, K. R. Shao, Y. G. Guo, J. G. Zhu, J. D. Lavers, "Improved sequential optimisation method for high dimensional electromagnetic optimisation problems," IEEE Trans. Magn., vol. 45, no. 10, pp. 3993-3996, Nov. 2009. 